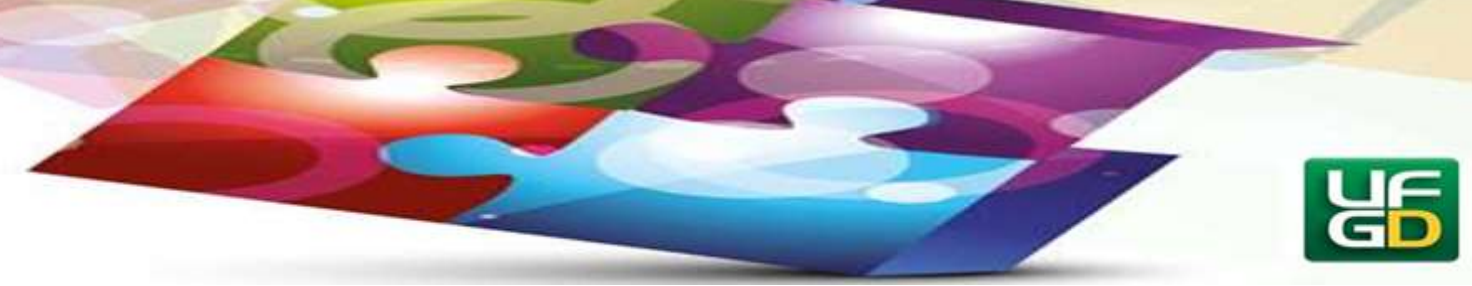

\title{
A PERCEPÇÃO DE PROFESSORES DA REDE ESTADUAL SOBRE A AVALIAÇÃO DA APRENDIZAGEM
}

\section{THE PERCEPTION OF TEACHERS FROM THE STATE'S EDUCATIONAL SYSTEM ABOUT THE ASSESSMENT OF LEARNING}

Jacimara Aparecida MENDES ${ }^{1}$

Fabio PERBONI ${ }^{2}$

Resumo: A presente pesquisa propõe-se a investigar as concepções de avaliação que predominam no âmbito escolar, tendo como sujeitos os docentes do Ensino Fundamental I de uma escola da Rede Estadual na cidade de Dourados/MS. A pesquisa é predominantemente qualitativa. Foi utilizado como instrumento de coleta de dados o questionário. A pesquisa apontou que os docentes utilizavam um método tradicional em suas práticas avaliativas, até mesmo quando em determinados momentos responderam utilizar um método avaliativo. Tais, resultados, longe de serem conclusivos, ajudam a compreender quais os conceitos que embasam a prática docente no momento de avaliar o seu aluno e a quem essa prática favorece no atual contexto educacional.

Palavras-chave: Ensino Fundamental. Avaliação Educacional. Aprendizagem. Concepção

\begin{abstract}
The present research proposes to investigate the conceptions of evaluation that predominate in the school scope, having as subjects the teachers of Elementary School I of a school of the State Network in the city of Dourados/MS. The research is predominantly qualitative. The questionnaire was used as a data collection instrument. The research pointed out that teachers used a traditional method in their evaluation practices, even when at certain times they responded using an evaluation method. Such results, far from being conclusive, help to understand which concepts are the basis of teaching practice when assessing your student and to whom this practice favors in the current educational context.
\end{abstract}

Keywords: Elementary School. Educational Assessment. Learning. Conception.

\footnotetext{
${ }^{1}$ Licenciada em Pedagogia e Letras. Docente da Educação Básica e Mestranda em Educação (FAED/UFGD). Email: jacimara.apmendes@gmail.com

${ }^{2}$ Doutor em Educação. Docente PPGEdu (FAED/UFGD) Email: fabioperboni@ufgd.edu.br
}

MENDES, Jacimara Aparecida.; PERBONI, Fabio. A PERCEPÇÃO DE PROFESSORES DA REDE ESTADUAL SOBRE A AVALIAÇÃO DA APRENDIZAGEM 


\section{Introdução}

A avaliação educacional tem sido tema de debates dentro e fora dos muros escolares, indaga-se sobre os reflexos da avaliação em relação a prática educativa, e também sobre os mecanismos e procedimentos de avaliação mais adequados.

A avaliação ocupa dentro das escolas um papel de destaque, pois ao colocá-la como o único método para aferir o suposto conhecimento de seus alunos, cria-se a ideia de que ela é o eixo central do aprendizado, pois não apresenta uma preocupação em saber se o aluno realmente aprendeu e tão pouco visa proporcionar ao alunos um ambiente com debates e pensamentos críticos, mas sim, se esse alcançou uma "boa nota".

Para Garcia (2003, p. 41),

Desaparecem o debate, a polêmica, as diferentes leituras do mesmo texto, o exercício da dúvida e de pensamento divergente, a pluralidade. A sala de aula se torna um pobre espaço de repetição, sem possibilidade de criação e circulação de novas ideias.

Esta pesquisa propõe-se a investigar as concepções de avaliação que predominam no âmbito escolar, tendo como sujeitos os docentes do Ensino Fundamental I de uma escola da Rede Estadual na cidade de Dourados/MS. Para embasar essa investigação é fundamental compreender que a avaliação recebe múltiplos significados dentro da escola. Contudo é compreendida de forma restrita, com base em procedimentos avaliativos ou apenas resultados representados por números.

Para Vasconcellos (2003) é importante avaliar o aluno, porém é muito mais importante avaliar a prática do professor, assim como avaliar a organização da escola, o currículo, a participação da comunidade, as condições de trabalho, como tudo que envolve e interfere no processo de ensino-aprendizagem. $\mathrm{O}$ autor faz indagações quanto ao papel do professor, pois aponta que na escola as crianças não aprendem só conhecimento. A escola tem uma função importantíssima na formação desse estudante.

A pesquisa inicia-se a partir de estudos que apontam para um cenário negativo sobre os processos avaliativos no interior das escolas, calçada em concepções tradicionais ou em compreensões restrita sobre o próprio conceito de avaliação.

A contribuição de autores como Hoffmann (1991; 2009), Vasconcellos (1995; 2003) Perrenoud (1998), Franco (2008), Esteban (2003) são fundamentais, pois, trazem definição de 
uma avaliação que privilegia a aprendizagem no processo educacional, considerando o aluno como o centro do processo. Além apontar outras formas possíveis de avaliar o aluno, sem colocá-lo em uma situação de constrangimento e exclusão social.

Hoffmann (1991) aponta os mitos e desafios que estão relacionados à avaliação, e a dificuldade que os professores têm em entender que avalição e aprendizagem fazem parte do mesmo processo.

Ao enfatizar a avaliação como um dos motivos para o fracasso escolar, Hoffmann (2009) aponta possibilidades para reverter este quadro negativo para a sociedade escolar, pois reconhecer que é falho faz parte do processo de mudança.

Vasconcellos (2003) coloca a avaliação como instrumento para ajudar no processo de aprendizagem e oferece várias formas para uma avaliação que contemple uma sociedade emancipada e crítica, sem que estas prejudiquem a vida escolar do aluno.

Perrenoud (1998) aponta que a avaliação deveria estar a serviço do ensino e não o contrário, ela jamais deveria impedir a inovação de uma pedagogia ativa e diferenciada.

Dessa forma, as características e os respectivos autores acima citados trazem relevantes contribuições para os objetivos que espera-se alcançar com esta pesquisa.

\section{Avaliação escolar}

Apesar de existir uma associação entre avaliação e espaço escolar, é importante enfatizar que os primeiros registros com essa temática surgem fora do espaço educacional, e cumpriam a função de classificar soldados para o exército chinês. A avaliação surge no espaço escolar, tal como é conhecida atualmente, apenas na modernidade.

[...] o exame foi um instrumento criado pela burocracia chinesa para eleger membros das castas inferiores. [...] existem inúmeras evidencias de que antes da Idade Média não existia um sistema de exames ligado à prática educativa. [...] a atribuição de notas ao trabalho escolar é uma herança do século XIX à pedagogia. Herança que produziu uma infinidade de problemas. Dos quais, hoje padecemos (BARRIGA, 2003, p. 55).

Mesmo não tendo origem no espaço educacional, a avaliação passa a ser utilizada dentro da escola “[...] como um instrumento de controle social. Na verdade é apenas no século XIX que se instala a qualificação escolar" (GARCIA, 2003, p. 41), sendo uma forma de manter sob controle os alunos.

É relevante pontuar que os testes padronizados ganham força em 1930, período em que Ralf W. Tyler e Smith, educadores americanos, padronizam os testes de forma a alcançar 
objetivos de mensurar a aprendizagem dos alunos por meio de vários métodos avaliativos, assim como “[...] testes, escalas de atitude, inventário, questionários, fichas de registros comportamentos (check lists) e outras medidas para colher evidências sobre rendimentos dos alunos numa perspectiva longitudinal [...]" (SAUL, 1995, p. 27).

Esses estudos chegam ao Brasil por meio de traduções e a partir desses trabalhos foram criados manuais que divulgavam e ensinavam essas práticas para os professores desse período, o que atualmente é conhecido como práticas avaliativas tradicionais. Com base nos métodos desenvolvidos por Tyler e Smith percebe-se que os autores defendiam uma avaliação de cunho empresarial e tecnicista, que atendia a uma sociedade de classes, privilegiando uma prática avaliativa que contemplasse a racionalização de conhecimento, criando uma desigualdade em relação às classes populares. É comum os professores avaliarem o aluno apenas atribuindo um número, que distingue o seu rendimento, às vezes bom, em outras circunstâncias ruins. Em desacordo a esse pensamento, muitos autores desenvolveram posicionamentos divergentes.

Neste contexto avaliativo é necessário fazer uma ressalva quanto à avaliação e nota, pois apesar de serem relacionadas instantaneamente, Vasconcellos (1995) distingue a avaliação como um processo amplo que faz parte da natureza humana, uma visão crítica sobre a prática, fazendo análise para se buscar meios para solucionar problemas. Enquanto a nota seja ela em forma de números, conceitos, ou menção, é uma exigência do processo educacional, e não uma necessidade para a aprendizagem.

\section{Concepções sobre avaliações}

A sociedade moderna vive um momento em que a palavra avaliação está presente em vários contextos sociais. Ela está presente em todas as esferas da sociedade, seja em um processo seletivo para a disputa por uma vaga de emprego, ou em uma avaliação para a disputa por uma bolsa de estudo. Avalia-se tudo, o tempo todo nas mais diversas situações do cotidiano.

Contudo no espaço escolar, a avaliação encontra-se mais presente, e ao contrário das outras esferas sociais, na escola ela encontra-se sistematizada, além de ser utilizada como uma ferramenta de controle. Sobre esse poder exercido pela avaliação cabe perguntar, "[...] sem a prova, o que obrigaria os alunos e alunas a estudar? Sem os prêmios e castigos, com seus mil apelidos e disfarces, como garantir a disciplina?” (ESTEBAN, 2003, p. 10).

Apesar de todos os professores utilizarem algum método avaliativo, entre os próprios professores há muitas divergências quanto à forma correta ou ideal para avaliar os seus alunos. 
Cabendo discussões quanto à problemática, mas de forma efetiva pouco tem sido feito para mudar essa prática avaliativa que vem enraizada há muito tempo.

Para Hoffmann (1991) avaliar é um conceito que busca aferir o quanto o aluno aprendeu, mas onde não importa o quanto o aluno sabe, o que cada professor busca avaliar é se o aluno aprendeu o que ele se propôs em ensinar, ou melhor, o que ele considera relevante para o currículo. Na maioria dos casos o professor espera uma única resposta, o que para a autora, seria um equívoco, pois o aluno não poderia ser avaliado somente sobre o seu erro, mas sim, pelas hipóteses que utilizou para chegar àquela resposta considerada errada. $\mathrm{O}$ fato de uma única resposta ser considerada a certa é considerada pela autora um equívoco. Há várias possibilidades de respostas para uma mesma pergunta, basta o professor abrir esse leque de opções e desconstruir este conceito de uma única resposta correta.

Outra função da avaliação é saber se o professor está conseguindo ensinar o conteúdo exigido, ou se sua proposta metodológica está falha. Contudo o que se percebe é que apenas o aluno é avaliado, enquanto o professor continua a cometer os mesmo equívocos, sem nenhuma reflexão, pois não entende que o fato de seu aluno não aprender também é um problema seu. Não cabe ao professor passar a responsabilidade para a família, pois é dever do professor ensinar, e mudar seus métodos quando necessário para alcançar este objetivo.

Em busca de compreender os conceitos de avaliação utilizou-se inicialmente a obra de Vasconcellos (2003) que distingue o conteúdo e a forma como duas dimensões essenciais na hora de avaliar. O conteúdo compreendido como o objeto da avaliação e forma compreendida a partir de como a avaliação acontecerá.

Considerando os conteúdos, a avaliação pode ser dividida entre várias modalidades, como: "auto-avaliação, avaliação do processo de ensino-aprendizagem, avaliação institucional, avaliação do sistema educacional e avaliação do sistema social" (VASCONCELLOS, 2003, p. 91). O autor aponta que é importante avaliar o aluno, mas que também se faz relevante avaliar a prática do professor, assim como avaliar a organização da escola, o currículo, a participação da comunidade, as condições de trabalho, como tudo que envolve e interfere no processo de ensino-aprendizagem.

Levando em conta que na escola as crianças não aprendem só conhecimento, “adquire também valores, hábitos, atitudes, desenvolve estruturas de pensamentos" (VASCONCELLOS, 2003, p. 92). A avalição pode ser dividida entre avalição cognitiva e avaliação sócio afetiva. A avaliação cognitiva busca medir o aprendizado que se refere a conhecimento, habilidade e operações, àquele conteúdo que é ensinado em sala de aula, enquanto a avaliação sócio afetiva diz respeito ao interesse, responsabilidade, comportamento 
e disciplina que cada criança apresenta no cotidiano escolar. Contudo observa-se que a avaliação cognitiva é mais presente dentro do âmbito escolar.

Segundo Vasconcellos (2003), não se deve confundir avaliação atitudinal com avaliação qualitativa e formativa, pois ambas são distintas em suas especificidades. $\mathrm{O}$ autor considera que mesmo dentro da avaliação sócio afetiva, a prática de atribuir nota é recorrente, justificada pelos professores como um método para resolver o problema da aprendizagem e disciplina. Vasconcellos (2003) aponta que mesmo ao utilizar a modalidade de avaliação sócio afetiva, os professores continuam cometendo os mesmo equívocos de atribuir um número aos alunos, contudo não modificam suas práticas e insistem em responsabilizar a família e a sociedade fora da escola como justificativa ao fracasso escolar de seus alunos.

Mesmo em relação à avaliação cognitiva mais valorizada no âmbito escolar por envolver o campo conceitual, aquele envolve a área do conhecimento, e que deve medir o conteúdo que foi dado em sala, os professores cometem equívocos recorrentes. Vasconcellos (2003) aponta que o professor ao avaliar seu aluno não deve esperar uma cópia do texto lido, que deve dar ao seu aluno o direito de expor seus pensamentos utilizando suas próprias palavras. O docente deve cobrar aquilo que foi dado, e sempre se questionar sobre a relevância do que foi ensinado em sala para seu aluno.

No que diz respeito às representações e práticas relativas à forma da avaliação, Vasconcellos (2003, p. 103) considera que essa prática "envolve rituais, as rotinas, os desdobramentos das diretrizes e normas, enfim, as maneiras de fazer e de expressar os resultados da avalição da aprendizagem”. O autor pontua que ao questionar sobre a avaliação processual, os professores costumam se confundir nesta prática, consideram que avaliação processual é a soma de "pontinhos", dar avaliação surpresa.

Quanto a isso Vasconcellos (2003) considera a avaliação processual como um processo contínuo, e deve haver um comprometimento por parte do docente em atender os seus alunos e aferir se aprenderam o que se propuseram a ensinar, e não dar várias provas para medir o conhecimento dos seus alunos. Outra interpretação equivocada quanto à avaliação processual, está na ideia, identificada pelo autor de que nesta avaliação não há registro, e que seria necessário apenas observar o aluno, mas o autor considera que nesta prática é necessário um conhecimento muito maior para que o professor possa acompanhar este aprendizado.

Quanto à questão do registro, Vasconcellos (2003) explica que é possível identificar duas modalidades de registro, que seria no processo e produto do processo. Ele define no processo aquele registro que acontece no momento em sala, com caráter mais descritivo, conhecido também como diário de bordo, nestes registros o professor aponta todos os 
acontecimentos considerados por ele relevantes, para que no momento futuro ele possa utilizar para melhorar a sua prática caso se faça necessário. O produto no processo é o registro de um determinado período, pode ser chamado de relatório, parecer descritivo, portfólio e etc. Segundo o autor os registros feitos pelo o professor são muito importantes para o desenvolvimento do trabalho docente, pois por meio das anotações é possível verificar, corrigir e criar estratégias para melhorar os resultados obtidos.

O autor aponta, ainda, o que poderia ser modificado pelos professores para desmistificar o monstro da avaliação, como: interagir até qualificar, diagnóstico rápido, questões a mais para escolha, avaliação com consulta, avaliação em grupo, não mudança no ritual, análise por amostragem, leitura de livro sem valor de nota, avaliação com fórmula, combate a competição e eliminação de uma das notas de conjunto. Primeiramente o autor coloca o que cada um pode fazer para modificar a prática avaliativa e em seguida pontua sobre os equívocos cometidos na hora de fazer as modificações, como: diversificação irrestrita das formas avaliativas, não fazer mais avaliação por escrito, ênfase na avaliação classificatória, criação de mecanismos formais, mudar apenas a superfície.

Para Vasconcellos (2003), os professores devem estar cientes do seu papel quanto à elaboração da prova escrita, preocupar-se em utilizar a prova como instrumento de aprendizagem e não como forma com-“prova"-ção. Segundo o autor a avaliação como instrumento deve ser clara, deve cobrar reflexão do seu aluno, essenciais, abrangentes, compatíveis com o que foi feito em sala, nada de exageros ou questões especiais por se tratar de prova. Durante a aplicação o professor deve estabelecer um ambiente de confiança, deixar clara as regras, fazer do momento de prova mais uma oportunidade de aprendizagem, previsão de tempo condizente com a resolução da prova. E ao entregar esta nota o professor não deve colocar seu aluno a uma situação de exposição, em caso de não alcançar os objetivos o professor deve trabalhar essas deficiências rapidamente, fazer uma autoavaliação, pois a avaliação também deve ser um meio de avaliar o seu próprio trabalho.

A avaliação está presente no espaço escolar desde o início da Educação Básica até a Universidade. O que gera desde muito cedo um clima de competição e individualismo entre os alunos. O intuito da avaliação é distinguir os alunos que aprenderam, daqueles que não conseguiriam alcançar a nota mínima necessária. Contudo a aprendizagem deixou de ser o foco principal e cedeu espaço para a nota necessária para "passar de ano". O estudante fica aprisionado a ideia de avaliação, o que gera contínuo conflito, confirmando a ideia de que a avalição tem deixado de cumprir o seu real propósito, e tem servido a uma sociedade 
excludente, na qual uma pequena parcela da sociedade domina os menos privilegiados, assim a avaliação seria uma forma de separar, filtrar e distinguir os alunos.

[...] a avaliação escolar não é só avaliação! De instrumento de análise do processo educacional, a avaliação tornou-se instrumento de dominação, de controle, de seleção social, de discriminação, de repressão, adquirindo até um caráter passional de vingança, de acerto de contas (VASCONCELLOS, 1995, p. 30).

Saul (1995) indica que a avaliação deixa de ser um instrumento útil no processo educacional para atender aos objetivos de um professor que busca penalizar o seu aluno, ou até mesmo controlá-lo. Neste contexto a avaliação passa a ser considerada desnecessária e objeto de repulsa por parte dos alunos. Neste sentido

A avaliação da aprendizagem, definida como uma das dimensões do papel do professor, transformou-se numa verdadeira "arma", em um instrumento de controle que tudo pode. Através desse uso exacerbado do poder, o professor mantém o silêncio, a "disciplina" dos alunos; [...] (SAUL, 1995, p. 48-49).

Os professores utilizam alguns métodos para avaliar os alunos, e as formas contempladas costumam ser sempre as mesmas, apesar de atender em alguns casos, alunos de diferentes idades e de diferentes contextos sociais. As dificuldades dos alunos e o seu contexto social não são observados. Em algumas situações os professores a utilizam, não como um instrumento de aprendizagem, mas sim, como um elemento coercitivo. Nesta situação, o aluno passa a ver a avaliação como um instrumento de punição e não como um instrumento no processo de aprendizagem.

A avalição, que impede a expressão de determinadas vozes, é uma prática de exclusão na medida em que vai selecionando o que pode e deve ser aceito na escola. [...] A avaliação funciona como instrumento de controle e de limitação das atuações (alunos/professores) no contexto escolar (ESTEBAN, 2003, p. 16).

Segundo Franco (2008), há desníveis no ensino brasileiro, pois pesquisas mostram que enquanto nas escolas públicas muitas crianças reprovam nos primeiros anos do ensino fundamental, um número bem reduzido de crianças que frequentam escolas privadas reprovam no mesmo ano escolar o que materializa em números o fracasso escolar

[...] quando sabemos que $50 \%$ das crianças da escola pública repetem a 1 série do ensino fundamental, enquanto essa porcentagem, entre aquelas que frequentam a rede de ensino privado, não chega a 5\% (FRANCO, 2008, p. 13).

Vasconcellos (1995, p. 14) aponta que "de cada 1000 alunos que iniciam a $1^{\text {a }}$ série do primeiro grau, somente 204 terminam a $8^{\mathrm{a}}$ série (21\%), dos quais somente 58 não repetiram um ano durante os 8 anos (6\%).” Por pensar nesta questão de fracasso e evasão busca-se cada vez 
mais entender quais os critérios utilizados pelos professores, pois estes tem em suas mãos o poder de proporcionar condições de mudança para a vida social desses estudantes.

Para Hoffmann (1991), a avalição passa a exercer um papel burocrático, em que envolve registros bimestrais, trimestrais e semestrais totalmente desvinculados da sua razão de ser no processo de construção do conhecimento. Os professores costumam avaliar seus alunos somente baseando-se na nota da prova, criando assim uma forma de controle sobre o aluno e um método excludente, pois muitos alunos não conseguem seguir esse ritmo imposto pela instituição escolar.

Segundo Esteban (2003), o espaço escolar se torna ainda mais excludente quando em uma avaliação os alunos que não vivenciaram determinadas experiências são prejudicados, seus conhecimentos são postos de lado, em detrimento de um saber elitizado e dominante, desse modo, "o fracasso escolar se configura dentro de um quadro de múltiplas negações, dentre as quais se coloca a negação da legitimidade de conhecimentos e formas de vida formulados à margem dos limites socialmente definidos como válidos” (ESTEBAN, 2003, p. 8). O que favorece um ambiente de exclusão e negação em relação a uma parte da sociedade, da qual a massa trabalhadora faz parte.

Segundo Franco ( 2008, p. 25), “[...] o fracasso escolar, a evasão e a repetência estão relacionados com a utilização de modelos inadequados, parciais e fragmentados de avaliação.” O professor precisa repensar suas práticas para que as mudanças possam acontecer, os professores em diversas situações apenas reproduzem aquilo que vivenciaram enquanto alunos. A falta de renovação perpetua a despreocupação com aqueles que não conseguem alcançar a nota mínima necessária, e dessa forma todos os anos, milhares de estudantes ficam pelo caminho, por acreditar que o seu conhecimento é insuficiente e pouco importante para o contexto escolar.

Para Esteban (2003), a avaliação escolar hoje é uma forma de exclusão, pois contempla um conhecimento mais elitizado em detrimento daquele que é produzido por uma classe social menos abastada, o que aumenta mais a exclusão e a desigualdade social. A desigualdade social é um fator importante no processo de aprendizagem, sendo reflexo de uma sociedade com sérios problemas sociais, que perpassa todas os direitos básicos, mas que tem resultados bem negativos na educação, ao que apenas ressalta o que se vê diariamente na sociedade brasileira. O cenário brasileiro aponta para uma desigualdade social que interfere diretamente no contexto educacional, confirmando o pensamento de que "não pode ser justo quando a estrutura social é injusta; não pode melhorar a educação quando existe uma drástica redução de subsídio e os docentes se encontram mal pagos; [...]” (BARRIGA, 2003, p. 57). 
A partir desses referenciais apresentados, serão analisados os dados coletados para identificar as concepções de avaliação presentes entre os docentes da escola selecionada.

\section{Procedimento Metodológico}

A pesquisa é predominantemente qualitativa, optou-se por essa abordagem por entender que se trata de um estudo que visa valorizar a análise dos dados. Segundo Cardano (2017), este tipo de abordagem permite ao pesquisador analisar com mais profundidade os menores detalhes diante do todo que compõe a pesquisa, cabendo ao pesquisador um olhar minucioso sobre todos os aspectos. Como instrumento de coleta de dados foi utilizado o questionário, que para Gil (2008, p. 121):

Pode-se definir questionário como a técnica de investigação composta por um conjunto de questões que são submetidos a pessoas com o propósito de obter informações sobre conhecimento, crenças, sentimentos, valores, interesses, expectativas, aspirações, temores, comportamento presente ou passado etc.

A pesquisa foi desenvolvida com 13 professores do Ensino Fundamental I de uma Escola da Rede Estadual do município de Dourados/MS. Os profissionais selecionados lecionavam em áreas diferentes, como: língua portuguesa, matemática, educação física, artes e pedagogos. Decidiu-se por incluir na pesquisa docentes de áreas por entender que todos deveriam praticar alguma forma de avaliação, e dessa forma, ao avaliar seus alunos utilizariam concepções plurais em suas práticas avaliativas. Os participantes da pesquisa atuavam na primeira etapa do Ensino Fundamental, ou seja, professores do $1^{\circ}$ ano ao $5^{\circ}$ ano dessa etapa de ensino.

O questionário aplicado foi composto por 13 questões fechadas e uma aberta, somando dessa forma 14 questões. Ao elaborar o questionário objetivou-se conhecer as percepções dos professores sobre avaliação. Devido às atividades diárias dos professores, foram necessários vários dias para que todos pudessem responder ao questionário da pesquisa. Os questionários foram aplicados nas salas dos professores durante suas respectivas Horas Atividades (HA), sendo aplicado nos momentos em que estavam disponíveis. Antes de iniciar o preenchimento dos questionários os professores foram orientados a ler o Termo de Livre Esclarecido (TLE), e em caso afirmativo a assinar o documento, concordando assim, em participar da pesquisa e autorizando que suas respostas fossem analisadas para a conclusão da pesquisa.

O Quadro abaixo demonstra o roteiro de perguntas elaboradas para o questionário e o que buscava-se compreender com cada questão, com base nos conceitos de Hoffmann (1991; 2009). Utiliza-se a escala Likert, em que os respondentes deveriam assinar seu nível de concordância ou discordância para cada afirmação. 
Quadro 1. Organização do Questionário Aplicado

\begin{tabular}{|c|c|}
\hline Perguntas do Questionário & Metas \\
\hline $\begin{array}{l}\text { Elaboro minhas avaliações constantemente da } \\
\text { mesma forma? }\end{array}$ & $\begin{array}{l}\text { Verificar se o professor utiliza métodos } \\
\text { diferentes para avaliar o seu aluno. }\end{array}$ \\
\hline $\begin{array}{l}\text { Quando identifico uma dificuldade de um aluno, } \\
\text { elaboro avaliações diferenciadas para ele? }\end{array}$ & $\begin{array}{l}\text { Verificar se diante de dificuldades por parte do } \\
\text { aluno o professor busca meios de privilegiar o } \\
\text { aprendizado }\end{array}$ \\
\hline $\begin{array}{l}\text { Pratico outras formas de avaliação, além da } \\
\text { avaliação escrita? }\end{array}$ & $\begin{array}{l}\text { Conhecer a concepção do professor sobre } \\
\text { avaliação. }\end{array}$ \\
\hline $\begin{array}{l}\text { Eu tenho dificuldades em elaborar provas e } \\
\text { avaliações que ajudem direcionar o processo de } \\
\text { aprendizagem dos alunos? }\end{array}$ & $\begin{array}{l}\text { Investigar se o professor tem um } \\
\text { posicionamento crítico sobre o seu trabalho. }\end{array}$ \\
\hline $\begin{array}{l}\text { Utilizo as notas obtidas por meio das avaliações } \\
\text { especificamente para aprovar ou reprovar? }\end{array}$ & $\begin{array}{l}\text { Verificar a opinião sobre a necessidade da prova } \\
\text { dentro do espaço escolar, e qual a sua aplicação. }\end{array}$ \\
\hline $\begin{array}{l}\text { Os resultados das avaliações dos meus alunos } \\
\text { influenciam as minha práticas pedagógicas? }\end{array}$ & Análise sobre a própria prática pedagógica. \\
\hline $\begin{array}{l}\text { Eu converso com os meus aluno sobre os } \\
\text { resultados das avaliações? }\end{array}$ & $\begin{array}{l}\text { Apurar se existe um momento de conversa sobre } \\
\text { a avaliação em si, para se discutir os resultados } \\
\text { obtidos por meio do instrumento. }\end{array}$ \\
\hline $\begin{array}{l}\text { As avaliações permitem que eu identifique as } \\
\text { dificuldades de cada aluno. }\end{array}$ & $\begin{array}{l}\text { Perceber qual o propósito de aferir o } \\
\text { aprendizado do aluno. }\end{array}$ \\
\hline $\begin{array}{l}\text { As avaliações auxiliam o professor a fazer uma } \\
\text { auto avaliação da sua prática docente. }\end{array}$ & $\begin{array}{l}\text { Saber se o professor tem ideia da importância do } \\
\text { seu papel nos resultados das avaliações. }\end{array}$ \\
\hline $\begin{array}{l}\text { A avaliação formal é uma maneira eficaz de } \\
\text { aferir o conhecimento dos alunos }\end{array}$ & $\begin{array}{l}\text { Identificar a concepção do professor sobre a } \\
\text { avaliação. }\end{array}$ \\
\hline $\begin{array}{l}\text { O grande número de alunos não permite } \\
\text { preparar atividades diferenciadas, conforme as } \\
\text { dificuldades de cada um }\end{array}$ & $\begin{array}{l}\text { Entender como os professores utilizam os } \\
\text { resultados das avaliações, e se o quantitativo de } \\
\text { alunos influenciam na forma como desenvolve o } \\
\text { seu trabalho pedagógico. }\end{array}$ \\
\hline $\begin{array}{l}\text { As avaliações externas contribuem para a } \\
\text { aprendizagem dos alunos. }\end{array}$ & $\begin{array}{l}\text { Averiguar a importância dada as avaliações e } \\
\text { como contribuem para o aprendizado dos alunos }\end{array}$ \\
\hline $\begin{array}{l}\text { Os resultados das avaliações externas são } \\
\text { suficientes para definir o desempenho das } \\
\text { instituições escolares }\end{array}$ & $\begin{array}{l}\text { Verificar qual a concepção do professor sobre os } \\
\text { resultados das avaliações em larga escala e } \\
\text { como interferem no trabalho deles }\end{array}$ \\
\hline
\end{tabular}




\begin{tabular}{|l|l|}
\hline $\begin{array}{l}\text { Indique as principais dificuldades que sente na } \\
\text { avaliação do seu aluno? }\end{array}$ & $\begin{array}{l}\text { Conhecer aflições que perpassam o pensamento } \\
\text { do professor quando avalia seu aluno. }\end{array}$ \\
\hline
\end{tabular}

Fonte: Questionário elaborado pela autora, 2018.

\section{Resultados}

A partir das análises das questões, foi possível perceber que os professores aparentam ter concepções homogêneas relacionadas à avaliação. As respostas apontaram que eles reconhecem a importância da avaliação e como ela pode influenciar na prática docente. Contudo, algumas repostas demonstraram inconsistência em determinados pontos.

Na questão 3 da I parte, dos 13 professores que participaram da pesquisa, quando questionados "Utilizo outras formas de avaliação, além da escrita?", apenas um professor respondeu que formativa e processual. O que chama a atenção é que esse mesmo profissional na parte seguinte do questionário, responde concordar que a avaliação formal é uma maneira eficaz de aferir o conhecimento dos alunos. O que é uma contradição em sua fala, considerando que a avaliação formativa, segundo Vianna é conhecida por acontecer durante todo o processo, seja para avaliar projetos, programas ou produtos, com essa finalidade é possível utilizar diversos instrumentos avaliativos, como anotações, observações, diário de bordo, sempre com o objetivo de "[...] proporcionar informações úteis para que os responsáveis possam promover o aprimoramento do que está sendo objeto de implementação" (VIANNA, 2000, p. 86). Enquanto a avaliação formal se localiza em posição inversa, completamente padronizada, visando a mensuração e a quantificação dos objetivos propostos e se utiliza de instrumentos "inclusive de comparações controladas e do uso de testes padronizados" (VIANNA, 2000. p. 127). Concordar que uma avaliação é a mais eficicaz, mas aplicar outra metodologia para avaliar soa no mínimo contraditório.

Quando questionados na parte II na questão 3 “A avaliação formal é uma maneira eficaz de aferir o conhecimento do aluno?" sete concordaram parcialmente, enquanto cinco discordaram parcialmente. O que aponta para um cenário em que as avaliações formais continuam ocupando um espaço significativo dentro das escolas, sinalizando para a predominância de uma prática avaliativa tradicional que em sua estrutura priorizam a seleção e a classificação, para esse fim “ as metodologias utilizadas são essencialmente de natureza quantitativas" (FERNANDES, 2010, p. 20). O que corrobora para um cenário pouco promissor no que se refere a outras formas de avaliar. 
As repostas dos professores sinalizaram para uma avaliação que auxilia no processo de ensino aprendizagem, contudo ao perguntar se "As avaliações externas contribuem para aprendizagem dos alunos", nove professores marcaram concordar parcialmente, enquanto quatro discordaram parcialmente. Este resultado indica que os professores consideram as avaliações externas como um auxílio para o aprendizado dos alunos, contudo estudos indicam que as avaliações externas não contribuem para o processo de ensino-aprendizagem. Pelo contrário ocupam um papel de regulação e desresponsabilização por parte do Estado. Além de serem organizadas de forma a quantificar por meio de números o conhecimento dos alunos.

$\mathrm{Na}$ questão seis da parte II, quando questionados se "Os resultados das avaliações externas são suficientes para definir o desempenho das instituições escolares" apenas quatro professores marcaram concordar parcialmente, enquanto nove professores discordaram da afirmativa. Esse resultado em especial demonstra o quanto o sistema educacional tende a buscar responsabilizar o aluno, pois segundo a maioria dos professores as avaliações auxiliavam no processo aprendizagem dos alunos, contudo não são suficientes para definir o desempenho das instituições de ensino, o que gera um conflito, como um pode ser desvinculado do outro? Visto que os resultados das avaliações em larga escala influenciam no status das escolas da Educação Básica, contribuindo para elencar educação e qualidade no mesmo contexto, ainda que isso não seja viável. Contudo quando os resultados não são positivos percebe-se um constrangimento frente a comunidade escolar, cabendo aos envolvidos no processor responder pelos resultados.

$\mathrm{Na}$ única questão aberta do questionário, "Indique as principais dificuldades que sente na avaliação do seu aluno", as respostas foram similares. Dentre os 13 professores, nove indicaram que "a falta de responsabilidade", "falta de interesse", "não estudam", "a família não ajuda", "falta de compromisso", "falta de comportamento na sala", "não se preparam para as avaliações", "não fazem tarefas”, são as grandes dificuldades encontradas na hora de avaliar o aluno. Um professor apontou não sentir dificuldades em avaliar seus alunos. Apenas três professores indicaram dificuldades que giravam em torno de número de alunos em sala, tempo disponível para as correções e avaliações, por essas razões apontaram não conseguir realizar um trabalho individualizado, outro professor respondeu que faltava recursos específicos, bancada e laboratório, para a elaboração de uma avaliação adequada para seus alunos, pois para a disciplina que lecionava seria viável uma avaliação diferenciada.

Percebeu-se que nove professores buscaram responsabilizar o aluno por uma dificuldade que o próprio docente aponta sentir. Ratificando um fato que acontece regularmente dentro das escolas. Em nenhuma das respostas os professores apontaram uma dificuldade que partisse deles, sempre responsabilizou o outro, fosse aluno, família ou o sistema educacional. A culpa 
pelas notas é, em geral, atribuída aos alunos e às famílias que não se esforçam o suficiente. Mas nunca ao professor que desenvolveu e ensinou em sala de aula.

$\mathrm{Na}$ questão 2, parte I "quando identifico uma dificuldade de um aluno, elaboro avaliações diferenciadas para ele?" sete professores responderam que elaboram avaliações diferenciadas para os seus alunos. Seis professores apontaram que poucas vezes, o que nos induz a pensar que mais de 50\% dos professores que participaram do questionário realizam atividades diferenciadas, contudo na questão 4 parte II, "O grande número de alunos não permite preparar atividades diferenciadas, conforme a dificuldade de cada um". 12 participantes disseram concordar com a assertiva, e apenas um participante respondeu discordar. Em uma questão os professores apontam que elaboram atividades diferenciadas, logo abaixo concordam que o grande número de alunos não permite elaborar atividades diferenciadas. Comparar as duas questões indicam uma inconstância nas respostas. Afinal, sabe-se que as salas de aula contam com um número alto de alunos, o que faz levantar a questão: Elaboram ou não, avaliações diferenciadas para os alunos que apresentam dificuldades?

\section{Considerações Finais}

As análises das respostas dos professores apontaram para uma situação comum nas escolas, que demonstram o quanto as avaliações são presentes nestes espaços. Todos os professores responderam avaliar seus alunos. Mesmo quando respondiam fazer avaliações diferenciadas, ainda assim indicavam que a avaliação formal era eficaz. Diante das suas dificuldades em avaliar os alunos todos indicaram fatores externos, que estavam fora de seu controle. Nenhum professor indicou uma dificuldade pessoal, que partisse dele e não do outro, A culpa não está na metodologia de ensino ou no método avaliativo utilizado pelo docente, mas sim, em outros fatores como: alunos, família, ou sistema educacional e etc. o que demonstra a incapacidade de se auto avaliar. Dessa forma o professor busca avaliar procurando aferir o que o aluno não sabe, mas não demonstra se preocupar com o conteúdo que não foi capaz de ensinar.

Percebe-se uma homogeneidade nas repostas dos docentes, que apontaram para percepções semelhantes. Foi possível observar que os docentes conhecem os pressupostos teóricos que embasam as práticas avaliativas, as respostas analisadas apontam para algumas inconsistências, pois mesmo diante de afirmações que preconizavam uma avaliação formativa, 
nas respostas seguintes via-se uma valorização da avaliação formal, que está diretamente relacionada com as práticas tradicionais de avaliação.

Em contra partida vários professores apontaram para a importância de respeitar as dificuldades individuais de cada aluno, aplicando avaliações diferenciadas quando necessário, contudo, um número considerável de professores afirma que o grande número de alunos em sala não permite preparar avaliações diferenciadas. O que gera uma incoerência nas informações prestadas, revelando um grande dilema enfrentado pelos professores, que gira em torno de saber o que é certo, mas fazer somente o que possível.

Diante das respostas apresentadas é possível assegurar que os docentes participantes utilizam um método tradicional em suas práticas avaliativas, até mesmo quando pensam estar utilizando um método que se difere desta prática. Percebe-se as práticas tradicionais presentes no contexto educacional, assim como nas respostas dos professores, pois mesmo quando apontam outras formas de avaliar ainda assim, consideram apenas o que estão solicitando, preocupando-se apenas em dar um número para aquela avaliação. Segundo Neves (2008) a avaliação tradicional é pautada em memorização, notas altas, obediência e passividade. O aluno que está fora desse parâmetro não é um aluno com potencial. Contudo é importante ressaltar que o aluno precisa se sentir parte de todo o processo, cabendo ao sistema educacional, formado pelo docente um ambiente no qual seja proporcionado ao aluno uma avaliação emancipadora, cooperando com um processo justo e igual a todos. Dessa forma,

\footnotetext{
quando a prática avaliativa reconhece no educando seu valor como pessoa, como sujeito de seu próprio desenvolvimento e como cidadão que tem direitos constituídos, toma uma grande distância da proposta tradicional (NEVES, 2008, p. 73).
}

Ao considerar o aluno como um sujeito único, repleto de significado e história o professor é capaz de realizar uma avaliação crítica que tenha como características a preocupação com a aprendizagem, além da busca por formar um cidadão questionador e autônomo, e não um cidadão que aceite o mundo de forma passiva.

Desse modo, espera-se que o presente trabalho ajude a fomentar as discussões acerca da avaliação da aprendizagem. É sabido que ainda há muito a ser estudado, planejado e produzido em torno do assunto, por essa razão, produções que procurem discutir e problematizar o ato de avaliar são pressurosos e necessários, para que modificações significativas aconteçam no processo de ensino-aprendizagem desenvolvido dentro dos espaços escolares.

\section{Referências}


BARRIGA, Ángel Díaz. Uma polêmica em relação ao exame. In: ESTEBAN, Maria Teresa (Org.). Avaliação: uma prática em busca de novos sentidos. 5. ed.- Rio de Janeiro: DP\&A, 2003.

ESTEBAN, Maria Teresa. A Avaliação no Cotidiano Escolar. In: ESTEBAN, Maria Teresa (Org.). Avaliação: uma prática em busca de novos sentidos. 5. ed.- Rio de Janeiro: DP\&A, 2003.

CARDANO, Mario. Manual de pesquisa qualitativa. A contribuição da teoria da argumentação. Tradução: Elisabeth da Rosa Conill. Petrópolis, Rio de Janeiro: Vozes, 2017.

FRANCO, Maria Laura P. Barbosa. Pressuposto Epistemológico da Avaliação Educacional. In: Sousa, C.P. de (Org.) Avaliação do Rendimento Escolar. 15. ed. Campinas: Papirus, 2008.

GARCIA, Leite Regina. A avaliação e suas implicações. No fracasso/sucesso In: ESTEBAN, Maria Teresa (Org), Avaliação: uma prática em busca de novos sentidos. 5. ed.- Rio de Janeiro: DP\&A, 2003.

GIL, Antonio Carlos. Métodos e Técnicas de Pesquisa Social. 6 ed. São Paulo, Atlas 2008.

HOFFMANN, Jussara. Avaliação: Mitos \& Desafios Uma perspectiva construtivista. 21. ed. Porto alegre; Educação e Realidade. 1991

HOFFMANN, Jussara. Avaliação mediadora: uma prática em construção da pré-escola à universidade. Porto Alegre; Editora Mediação, 2009.

NEVES, Isabel Cristina. Avaliação da Aprendizagem: concepções e práticas de formadores de professores. Guarapuava; Unicentro. 2008.

PERRENOUD, Philippe. Avaliação: da excelência à regulação das aprendizagens - entre duas lógicas. Porto Alegre: Artmed, 1998.

SAUL, Ana Maria. Avaliação Emancipatória Desafios à teoria e à prática de Avaliação e reformulação de Currículo. Ed.Cortez 2 ed. 1996.

SOUSA, Sandra Zakia Lian. Revisando a teoria da avaliação da aprendizagem. In: Sousa, C.P. de (Org). Avaliação do Rendimento Escolar. 15. ed. Campinas: Papirus, 2008.

VASCONCELlOS, Celso dos S. Avaliação: Concepção Dialética-Libertadora do Processo de Avaliação Escolar. São Paulo: Libertad, 1995.

VASCONCELlOS, Celso dos S. Avaliação da Aprendizagem - Práticas de Mudança: por uma práxis transformadora. São Paulo: Libertad, 2003.

VIANNA, Heraldo Marelin. Avaliação Educacional: teoria-planejamento-modelos. São Paulo, ed Ibrasa, 2000 